\title{
OS SABERES DA EXPERIÊNCIA E SUAS IMPLICAÇÕES NA PRÁTICA PEDAGÓGICA DE PROFESSORES DE EDUCAÇÃO FÍSICA DA EDUCAÇÃo BÁSICA EM DIFERENTES FASES DA CARREIRA
}

\author{
THE KNOWLEDGE OF EXPERIENCE AND ITS IMPLICATIONS IN THE \\ PEDAGOGICAL PRACTICE OF PHYSICAL EDUCATION TEACHERS IN BASIC \\ EDUCATION IN DIFFERENT PHASES OF THE CAREER
}

Hugo Norberto Krug
${ }^{1}$
Marília de Rosso Krug
Rodrigo de Rosso Krug
Moane Marchesan Krug

\begin{abstract}
RESUMO
O estudo objetivou analisar as percepções de professores de Educação Física (EF) da Educação Básica (EB), da rede pública de ensino, de uma cidade da região central do estado do Rio Grande do Sul (Brasil), sobre os seus saberes da experiência e as suas implicações na prática pedagógica, em diferentes fases da carreira. Caracterizamos a pesquisa como qualitativa do tipo estudo de caso. O instrumento de pesquisa foi um questionário, tendo as informações coletadas interpretadas pela análise de conteúdo. Participaram vinte e cinco professores de EF da EB da referida rede de ensino e cidade. Concluímos que os saberes da experiência permeiam todas as fases da carreira dos professores de EF da EB estudados e que o principal foi o saber lidar com as condições de trabalho difíceis/precárias.
\end{abstract}

Palavras-chave: educação física. educação física escolar. prática pedagógica. saberes da experiência.

\begin{abstract}
The study was aimed to analyze the perceptions of Physical Education (PE) teachers of Basic Education (BE), from the public school network, of a city in the central region of the state of Rio Grande do Sul (Brazil), about their knowledge of the experience and its implications for pedagogical practice at different phases of the career. We characterize the work as qualitative research of the case study type. The research instrument was a questionnaire, the collected information interpreted by the content analysis. Twenty-five PE teachers from BE of that education network and city referred participated. We conclude that the knowledge of the experience permeates all phases of the career of the PE teachers of the BE studied, and that the main one was the knowledge to deal with the difficult/precarious working conditions.
\end{abstract}

Keywords: physical education. school physical education. pedagogical practice. knowledge of experience.

\footnotetext{
${ }^{1}$ Doutor em Educação (UNICAMP/UFSM); Doutor em Ciência do Movimento Humano (UFSM); Professor Aposentado do Departamento de Metodologia do Ensino do Centro de Educação da Universidade Federal de Santa Maria (UFSM); hnkrug@ bol.com.br.

${ }^{2}$ Doutora em Educação em Ciências: Química da Vida e Saúde (UFSM); Professora do Programa de PósGraduação em Atenção Integral à Saúde (Mestrado) da Universidade de Cruz Alta (UNICRUZ); mkrug@unicruz.edu.br.

${ }^{3}$ Doutor em Ciências Médicas (UFSC); Professor do Programa de Pós-Graduação em Atenção Integral à Saúde (Mestrado) da Universidade de Cruz Alta (UNICRUZ); rodkrug@ bol.com.br.

${ }^{4}$ Doutora em Educação Física (UFSC); Professora Adjunta do Departamento de Humanidades e Educação da Universidade Regional do Noroeste do Estado do Rio Grande do Sul (UNIJUÍ); Professora Tutora do Programa de Pós-Graduação Multidisciplinar em Saúde da Família; moane.krug@unijui.edu.br.
} 


\section{AS CONSIDERAÇÕES INICIAIS}

Segundo Krug et al. (2015, p.79), em tempos recentes, “[...] na área educacional, têmse verificado um aumento significativo de estudos que procuram investigar as especificidades, a natureza e os processos de construção de conhecimentos ou saberes de professores". Nesse sentido, citamos alguns estudos sobre esta temática: Krug et al. (2017); Casarotto e Krug (2016); Krug et al. (2016a); Contreira e Krug (2015); Krug (2015); Krug et al. (2015); Telles et al. (2015); Conceição; Krug e Venson (2013); Antunes e Krug (2011); Conceição; Sousa e Krug (2010); Krug e Krug (2010); e, Bernardi e Krug (2008).

Assim, no cenário da escola, Bernardi e Krug (2008, p. 66) alertam que "[a] escola é palco de diferentes influências, políticas, sociais, culturais e econômicas, onde todos estes fatores influenciam e são influenciados pelos atores que da escola fazem parte, entre eles os professores e os alunos". Destacam que emergem deste contexto escolar conhecimentos que implicam diretamente e indiretamente na atuação docente. São saberes que "[...] podem ser chamados de escolares, que atravessam o ambiente escolar, e que estão incorporados na relação entre os professores, com os alunos, do professor com o conteúdo das disciplinas. Formam uma rede de saberes e saber-fazer que juntos vão construindo [...]" a atuação docente (BERNARDI; KRUG, 2008, p. 66).

Desta forma, no desenrolar da atuação do professor, integra a sua prática diferentes saberes, como salienta Tardif (2002), com os quais mantêm diferentes relações, pois se pode definir o saber docente como um saber plural, formado pelo amálgama, mais ou menos coerente, de saberes oriundos de diversas fontes.

Antunes e Krug (2011, p. 2-3) ao se referirem à obra de Maurice Tardif intitulada 'Saberes docentes e formação profissional' destacam que o autor classifica os saberes docentes da seguinte forma:

[...] a) Saberes da formação profissional, são um conjunto de saberes transmitidos pelas instituições de formação de professores; b) Saberes disciplinares, correspondem aos diversos campos do conhecimento, [...], integrados nas universidades, sob forma de disciplinas, no interior de faculdades e cursos distintos; c) Saberes curriculares, correspondem aos discursos, objetos, conteúdos e métodos a partir dos quais a instituição escolar categoriza e apresenta os saberes sociais por ela definidos e selecionados como modelos da cultura erudita e de formação para a cultura erudita; e, d) Saberes experenciais ou práticos, são os saberes baseados no trabalho cotidiano e no conhecimento de seu meio, brotam da experiência individual e coletiva de saber fazer e saber ser.

Já Pimenta (2012) aponta três tipos de saberes: a) os saberes pedagógicos - são aqueles provenientes dos conhecimentos das ciências educacionais; b) os saberes específicos 
- são aqueles referentes às disciplinas que o professor leciona; e, c) os saberes experenciais são aqueles provenientes das ações de ensinar, nascem da prática pedagógica.

De acordo com Lourencetti e Mizukami (2002), existe um consenso em que a prática pedagógica integra diversos tipos de conhecimentos e/ou saberes que são elaborados ao longo do exercício da docência. Assim, os professores incorporam ou mesmo se apropriam de experiências variadas, conhecimentos, teorias, crenças, etc.

Neste sentido, Larrosa (2002) coloca que a experiência é algo que marca nossas vidas, é algo que nos acontece e nos causa inquietude. A experiência constitui-se ao longo do processo de ser e tornar-se humano e consequentemente de ser e tornar-se professor. Para o autor, a experiência não é vivência, pois essa passa pelas nossas vidas sem deixar marcas. A experiência deixa rastros na história de uma vida, deixa lembranças que nunca serão esquecidas.

Assim, neste cenário dos saberes docentes, especificamente dos saberes da experiência e/ou experenciais foi que deslocamos o interesse investigativo do professorado em geral para os professores de Educação Física (EF) da Educação Básica (EB) em específico, bem como para as implicações destes na prática pedagógica.

Diante deste cenário, de implicações dos saberes da experiência e/ou experenciais na prática pedagógica foi que emergiu o entrelaçamento das mesmas com as fases da carreira de professores de EF da EB.

Nesta direção de proposição, citamos Huberman (1995) que diz que a carreira é um processo e não uma série de acontecimentos, pois, para alguns, esse processo é linear, mas para outros, há patamares, regressões, becos sem saída, momentos de arranque e descontinuidades, sendo então, um processo complexo, em que fases da vida e da profíssão se entrelaçam ao longo do tempo. Esse autor foi o pioneiro em estudar a carreira do professor e a classifica em ciclos de vida profissional, denominando-as como fases, que são as seguintes: $1^{a}$ ) entrada na carreira (até 3 anos de docência); $2^{\text {a }}$ ) estabilização (dos 4 aos 6 anos de docência); $3^{\text {a }}$ ) diversificação (dos 7 aos 15 anos de docência); $4^{\text {a }}$ ) serenidade e/ou conservantismo (dos 15 aos 30 anos de docência); e, $5^{\text {a }}$ ) desinvestimento (dos 30 aos 35 anos de docência).

Desta forma, considerando as premissas anteriormente descritas defrontamo-nos com a seguinte questão problemática norteadora do estudo: quais são as percepções de professores de EF da EB, da rede pública de ensino, de uma cidade da região central do estado do Rio Grande do Sul - RS (Brasil), sobre os seus saberes da experiência e as suas implicações na prática pedagógica, em diferentes fases da carreira? 
A partir desta indagação, o estudo teve como objetivo geral, analisar as percepções de professores de $\mathrm{EF}$ da $\mathrm{EB}$, da rede pública de ensino, de uma cidade da região central do estado do Rio Grande do Sul - RS (Brasil), sobre os seus saberes da experiência e as suas implicações na prática pedagógica, em diferentes fases da carreira.

Justificamos a realização deste estudo, ao citarmos Krüger e Krug (2008) que destacam que à medida que os professores vão acumulando experiência como docente, possuem a capacidade de modificar algumas de suas idéias anteriores, passando, então, a (re)significarem os seus saberes.

\section{OS PROCEDIMENTOS METODOLÓGICOS}

Caracterizamos a pesquisa como qualitativa do tipo estudo de caso.

Para Denzin e Lincon (2008 apud MORETTI-PIRES; SANTOS, 2012, p. 18), “[...] a pesquisa qualitativa se caracteriza como tal pela ênfase na qualidade das entidades, processos e significados dos fenômenos investigados [...]”.

Segundo Yin (2009 apud ALMEIDA; OPPA; MORETTI-PIRES, 2012, p. 143), no estudo de caso "[...] busca-se qualificar as características encontradas como forma de conhecimento para tentar entender um fenômeno específico, pouco conhecido em um contexto articulado com a vida-real".

A coleta de informações foi efetuada por meio de um questionário, que, de acordo com Aragão e Moretti-Pires (2012, p. 184), “[o] questionário aparece no cenário da pesquisa (qualitativa) como [...] um meio para obtenção de dados [...]" (inserção nossa).

A interpretação das informações foi realizada por meio da análise de conteúdo, que, conforme Franco (2008), possui as seguintes etapas: $1^{\text {a }}$ ) a leitura flutuante - que procura compreender os direcionamentos e tendências de respostas dos colaboradores; $2^{\mathrm{a}}$ ) a sistematização das unidades de registro - que analisa as informações oriundas do instrumento de pesquisa; e, $3^{\mathrm{a}}$ ) a organização das unidades de contexto - que é a unidade básica de registro que permite as inferências, bem como a articulação em categorias temáticas. Nesse sentido, as categorias foram estabelecidas a posteriori da posse das análises realizadas.

Participaram do estudo vinte e cinco professores de EF da EB, de uma rede pública de ensino, de uma cidade da região central do estado do RS (Brasil), sendo cinco de cada fase da carreira docente apontada por Huberman (1995), isto é, entrada na carreira, estabilização, diversificação, serenidade e/ou conservantismo e desinvestimento, pois, segundo Krug et al. (2019b, p. 15), “[...] os professores situados em cada fase te[m] mais pertinência para opinar sobre a temática em questão, já que as esta[riam] vivenciando na ocasião da coleta de 
informações". Dessa maneira, a escolha dos participantes do estudo aconteceu de forma intencional. Esse fato está em consonância com o dito por Rojas-Soriano (2004 apud BERRIA et al., 2012, p. 159) de que "[a] seleção dos informantes em pesquisa qualitativa parte da amostra intencional [...]”, “[...] na qual o pesquisador seleciona os sujeitos por juízo particular, como conhecimento do tema ou representatividade subjetiva" (BERRIA et al., 2012, p. 159).

Em relação aos aspectos éticos vinculados às pesquisas científicas apontamos que todos os participantes (colaboradores) assinaram o Termo de Consentimento Livre e Esclarecido e suas identidades foram preservadas.

\section{OS RESULTADOS E AS DISCUSSÕES}

Os resultados e as discussões foram orientados e explicitados pelo objetivo geral do estudo, pois esse representou a temática estudada (saberes da experiência, em diferentes fases da carreira docente). Assim, a seguir, apresentamos o que expuseram os professores de EF da EB estudados, sobre a temática em questão, considerando as categorias temáticas, originadas pelas unidades de contexto.

No quadro 1 apresentamos as categorias temáticas relativas aos saberes da experiência, nas percepções dos professores de EF da EB estudados, em diferentes fases da carreira docente.

Quadro 1 - Os saberes da experiência, nas percepções dos professores de EF da EB estudados, em diferentes fases da carreira.

\begin{tabular}{|c|c|c|c|c|c|c|}
\hline \multirow[b]{2}{*}{$\begin{array}{l}\text { Saberes da } \\
\text { experiência }\end{array}$} & \multicolumn{5}{|c|}{ Fases da carreira docente } & \multirow{2}{*}{$\begin{array}{l}\text { Total } \\
\text { de } \\
\text { cita- } \\
\text { ções }\end{array}$} \\
\hline & $\begin{array}{c}\text { En- } \\
\text { tra- } \\
\text { da }\end{array}$ & $\begin{array}{c}\text { Esta- } \\
\text { bili- } \\
\text { zação }\end{array}$ & $\begin{array}{l}\text { Diver- } \\
\text { sifica- } \\
\text { ção }\end{array}$ & $\begin{array}{l}\text { Serenid./ } \\
\text { Conser- } \\
\text { Vantismo }\end{array}$ & $\begin{array}{l}\text { Desin- } \\
\text { vesti- } \\
\text { mento }\end{array}$ & \\
\hline $\begin{array}{l}\text { 1)Saber lidar com as condições de trabalho } \\
\text { difíceis/precárias* }\end{array}$ & 1 & 3 & 5 & 5 & 5 & 19 \\
\hline $\begin{array}{l}\text { 2)Saber lidar com os comportamentos } \\
\text { indisciplinados dos alunos** }\end{array}$ & 1 & 2 & 3 & 4 & 5 & 15 \\
\hline $\begin{array}{l}\text { 3)Saber lidar com a falta de interesse dos alunos } \\
\text { pelas atividades propostas** }\end{array}$ & - & 1 & 2 & 3 & 4 & 10 \\
\hline $\begin{array}{l}\text { 4)Saber evitar os conflitos com os colegas de } \\
\text { trabalho*** }\end{array}$ & - & - & 2 & 3 & 3 & 8 \\
\hline 5)Saber trabalhar coletivamente na escola*** & - & - & 3 & 2 & 1 & 6 \\
\hline $\begin{array}{l}\text { 6)Saber fazer um bom planejamento de ensino } \\
\text { para as aulas de } \mathrm{EF}^{* * *}\end{array}$ & 1 & 1 & - & 1 & 2 & 5 \\
\hline $\begin{array}{l}\text { 7)Saber ter controle/domínio da turma de } \\
\text { alunos** }\end{array}$ & - & 1 & 1 & 1 & 1 & 4 \\
\hline 8)Saber mais sobre gestão de aula*** & 1 & - & - & - & - & 1 \\
\hline Quantidade de saberes da experiência & 4 & 5 & 6 & 7 & 7 & 8 \\
\hline Total de citações & 4 & 8 & 16 & 19 & 21 & 68 \\
\hline
\end{tabular}


Legenda: *Saber da experiência ligado à estrutura da escola/sistema educacional; **Saber da experiência ligado aos alunos da EB; ***Saber da experiência ligado aos próprios professores, ou seja, a si mesmos.

Fonte: Organizado pelos autores.

No quadro 1 podemos observar a existência de um rol de 'oito' categorias temáticas que representaram os saberes da experiência, nas percepções dos professores de EF da EB estudados, nas diferentes fases da carreira docente. Foram eles:

1) 'Saber lidar com as condições de trabalho difíceis/precárias'*, expressas pela falta de espaços físicos e de materiais para as aulas de EF (dezenove citações). Em referência a esse saber da experiência citamos Krug et al. (2019a, p. 230) que constataram que "[a]s condições de trabalho difíceis/precárias, expressas pela falta de espaços físicos e de materiais para as aulas de EF [...]" é uma das dificuldades pedagógicas de professores de EF na EB, em diversas fases da carreira. Já Krug et al. (2019b, p. 18) apontam que "[a] falta de condições de trabalho da EF na escola [...]" é um dos fatores indicativos de insatisfação profissional de professores de EF da EB, em diferentes fases da carreira. Assim sendo, podemos inferir que 'as condições de trabalho difíceis/precárias, ao ser uma dificuldade pedagógica que provoca a insatisfação profissional pode, com certeza, vir a ser uma implicação de interferência negativa na prática pedagógica dos professores de EF da EB, em diferentes fases da carreira'. Entretanto, frente a esse cenário inferido, mencionamos Krug (2019a, p. 8) que coloca que "[a] existência de um adequado espaço físico destinado ao desenvolvimento das aulas de EF na escola [...]" e "[a] existência de materiais adequados para o desenvolvimento das aulas de EF na escola [...]" é um dos fatores que facilitam a prática pedagógica dos professores de EF da EB. Nesse sentido, Krug et al. (2019c, p. 26) afirmam que "[...] saber dar aula de EF em condições de trabalho difíceis/precárias [...]" é uma das necessidades formativas de professores de EF na EB. Dessa forma, podemos inferir que 'saber lidar com as condições de trabalho difíceis/precárias, ao ser uma facilidade na prática pedagógica e uma necessidade formativa pode, com certeza, vir a ser uma implicação de interferência positiva na prática pedagógica dos professores de EF da EB, em diferentes fases da carreira, tornando-se assim, um saber da experiência';

2) 'Saber lidar com os comportamentos indisciplinados dos alunos'** (quinze citações). Sobre esse saber da experiência nos referimos a Krug et al. (2019a, p. 231) que constataram que "[a] indisciplina dos alunos [...]" é uma das dificuldades pedagógicas de professores de EF na EB, em diversas fases da carreira. Já Krug et al. (2019, p. 18) colocam que "[a] indisciplina dos alunos [...]" é um dos fatores indicativos de insatisfação profissional de 
professores de EF da EB, em diferentes fases da carreira. Assim sendo, podemos inferir que 'os comportamentos indisciplinados dos alunos, ao ser uma dificuldade pedagógica que provoca a insatisfação profissional pode, com certeza, vir a ser uma implicação de interferência negativa na prática pedagógica dos professores de EF da EB, em diferentes fases da carreira'. Entretanto, frente a esse cenário inferido, nos referimos a Krug (2019a, p. 8) que aponta que "[a]lunos indisciplinados nas aulas de EF na escola [...]" é um dos fatores que facilitam a prática pedagógica dos professores de EF da EB. Nesse sentido, Krug et al. (2019c, p. 26) dizem que "[s]aber lidar com os alunos indisciplinados [...]" é uma das necessidades formativas de professores de EF na EB. Dessa forma, podemos inferir que 'saber lidar com os comportamentos indisciplinados dos alunos, ao ser uma facilidade na prática pedagógica e uma necessidade formativa pode, com certeza, vir a ser uma implicação de interferência positiva na prática pedagógica dos professores de $\mathrm{EF}$ da $\mathrm{EB}$, em diferentes fases da carreira, tornando-se assim, um saber da experiência';

3) 'Saber lidar com a falta de interesse dos alunos pelas atividades propostas'** (dez citações). Diante desse saber da experiência mencionamos Krug et al. (2019a, p. 231) que constataram que "[a] falta de interesse dos alunos pelas atividades propostas [...]" é uma das dificuldades pedagógicas de professores de EF na EB, em diversas fases da carreira. Já Krug et al. (2018, p. 36) apontam que "[a] falta de interesse dos alunos pelas atividades propostas [...]" é um dos desafios docentes no cotidiano educacional de professores de EF da EB, em diferentes fases da carreira. Assim sendo, podemos inferir que 'a falta de interesse dos alunos pelas atividades propostas, ao ser uma dificuldade pedagógica e um desafio docente pode, com certeza, vir a ser uma implicação de interferência negativa na prática pedagógica dos professores de EF da EB, em diferentes fases da carreira'. Entretanto, frente a esse cenário inferido, nos dirigimos a Krug (2019a, p. 8) que coloca que "[o] interesse dos alunos pelas atividades propostas pelo professor nas aulas de EF na escola [...]" é um dos fatores que facilitam a prática pedagógica dos professores de EF da EB. Nesse sentido, Krug et al. (2019c, p. 26) ressaltam que "[s]aber lidar com a falta de interesse dos alunos pelas atividades propostas [...]" é uma das necessidades formativas de professores de EF na EB. Dessa forma, podemos inferir que 'saber lidar com a falta de interesse dos alunos pelas atividades propostas, ao ser uma facilidade na prática pedagógica e uma necessidade formativa pode, com certeza, vir a ser uma implicação de interferência positiva na prática pedagógica dos professores de EF da EB, em diferentes fases da carreira, tornando-se assim, um saber da experiência'; 
4) 'Saber evitar os conflitos com os colegas de trabalho'*** (oito citações). No direcionamento desse saber da experiência utilizamos Krug et al. (2019a, p. 234) que colocam que "[o]s conflitos com os colegas de trabalho [...]" é uma das dificuldades pedagógicas de professores de EF na EB, em diversas fases da carreira. Já Krug et al. (2019b, p. 19) destacam que "[o] conflito com os colegas professores [...]” é um dos fatores indicativos de insatisfação profissional de professores de $\mathrm{EF}$ da $\mathrm{EB}$, em diferentes fases da carreira. Assim sendo, podemos inferir que 'os conflitos com os colegas de trabalho, ao ser uma dificuldade pedagógica que provoca a insatisfação profissional pode, com certeza, vir a ser uma implicação de interferência negativa na prática pedagógica dos professores de EF da EB, em diferentes fases da carreira'. Entretanto, frente a esse cenário inferido, nos referimos a Rebelo (2012) que destaca que o trabalho do professor é marcado pelas relações interpessoais e, quando essas são positivas, podem promover um ambiente favorável e amigável, sendo determinantes para o sucesso do ensino e o bem-estar do professor. Já, segundo Krug et al. (2020, p. 146), “[...] o respeito [...] entre as pessoas na escola influencia nas [...] atividades docentes [...] auxiliando-as [...]". Dessa forma, podemos inferir que "saber evitar os conflitos com os colegas de trabalho, ao necessitar de relações interpessoais positivas que auxiliam na boa execução das atividades docentes pode, com certeza, vir a ser uma implicação de interferência positiva na prática pedagógica dos professores de $\mathrm{EF}$ da $\mathrm{EB}$, em diferentes fases da carreira, tornando-se assim, um saber da experiência';

5) 'Saber trabalhar coletivamente na escola'*** (seis citações). Evidenciamos esse saber da experiência nos fundamentando em Krug et al. (2019a, p. 234) que constataram que "[o] isolamento profissional docente [...]" é uma das dificuldades pedagógicas de professores de EF na EB, em diversas fases da carreira. Já Krug et al. (2019b, p. 37) indicam que "[o] isolamento profissional docente [...]" é um dos fatores indicativos de insatisfação profissional de professores de EF da EB, em diferentes fases da carreira. Assim sendo, podemos inferir que 'o isolamento profissional docente, ao ser uma dificuldade pedagógica que provoca a insatisfação profissional pode, com certeza, vir a ser uma implicação de interferência negativa na prática pedagógica dos professores de EF da EB, em diferentes fases da carreira'. Entretanto, frente a esse cenário inferido, lembramos Krug (2019a, p. 9) que aponta que "[u]m trabalho coletivo desenvolvido pelos professores da escola [...]" é um dos fatores que facilitam a prática pedagógica dos professores de EF da EB. Nesse sentido, Krug et al. (2019c, p. 27) destacam que "[...] compreender as causas e as consequências do isolamento docente [...]" é uma das necessidades formativas de professores de EF na EB. Dessa forma, podemos inferir que 'saber trabalhar coletivamente na escola, ao ser uma facilidade na prática 
pedagógica e uma necessidade formativa pode, com certeza, vir a ser uma implicação de interferência positiva na prática pedagógica dos professores de $\mathrm{EF}$ da $\mathrm{EB}$, em diferentes fases da carreira, tornando-se assim, um saber da experiência';

6) 'Saber fazer um bom planejamento de ensino para as aulas de EF'*** (cinco citações). Esse saber da experiência encontra suporte em Krug et al. (2019a, p. 232) que constataram que "[a] dificuldade no planejamento das aulas [...]" é uma das dificuldades pedagógicas de professores de EF na EB, em diversas fases da carreira. Já, segundo Krug et al. (2016b), a falta de planejamento de ensino para as aulas faz parte da cultura da EF na escola. Assim sendo, podemos inferir que 'não fazer planejamento de ensino para as aulas, ao ser uma dificuldade pedagógica e uma cultura da EF Escolar pode, com certeza, vir a ser uma implicação de interferência negativa na prática pedagógica dos professores de EF da EB, em diferentes fases da carreira'. Entretanto, frente a esse cenário inferido, citamos Krug (2019a, p. 9) que aponta que "[a] existência de um bom planejamento do professor para as aulas de EF na escola [...]" é um dos fatores que facilitam a prática pedagógica dos professores de EF da EB. Nesse sentido, Ilha; Marques e Krug (2009, p. 2) destacam que "[u]m dos aspectos de maior relevância na prática pedagógica dos professores refere-se ao planejamento de suas aulas, pois ele orienta toda a docência do professor, para que este desenvolva um trabalho sério, coerente e com continuidade [...]". Dessa forma, podemos inferir que 'saber fazer um bom planejamento de ensino para as aulas de EF, ao ser uma facilidade na prática pedagógica, pois orienta toda a docência pode, com certeza, vir a ser uma implicação de interferência positiva na prática pedagógica dos professores de EF da EB, em diferentes fases da carreira, tornando-se assim, um saber da experiência';

7) 'Saber ter o controle/domínio da turma de alunos'** (quatro citações). Quanto a esse saber da experiência apontamos Krug et al. (2019a, p. 235) que constataram que "[a] falta de controle/domínio da turma de alunos [...]" é uma das dificuldades pedagógicas de professores de EF na EB, em diversas fases da carreira. Já Marques e Krug (2009 apud Krug et al., 2016c, p. 21) colocam que “[...] a falta de controle/domínio da turma de alunos [...]” é um dos dilemas da prática pedagógica de professores de EF da EB. Assim sendo, podemos inferir que 'a falta de controle/domínio da turma de alunos, ao ser uma dificuldade e um dilema da prática pedagógica pode, com certeza, vir a ser uma implicação de interferência negativa na prática pedagógica dos professores de $\mathrm{EF}$ da EB, em diferentes fases da carreira'. Entretanto, frente a esse cenário inferido indicamos Krug (1996) que diz que a atividade do professor é objeto do desenvolvimento da competência pedagógica, portanto ela se aperfeiçoa plenamente com o exercício da docência e com a utilização de novos conhecimentos. Nesse sentido, Krug 
(2020, p. 9) aponta que uma das características do bom professor de EF da EB é "[t]e[r] o controle/domínio da turma de alunos [...]". Dessa forma, podemos inferir que "saber ter o controle/domínio da turma de alunos, ao ser um objeto do desenvolvimento da competência pedagógica do professor e uma característica do bom professor pode, com certeza, vir a ser uma implicação de interferência positiva na prática pedagógica dos professores de EF da EB, em diferentes fases da carreira, tornando-se assim, um saber da experiência'; e,

8) 'Saber mais sobre gestão de aula'*** (uma citação). Esse saber da experiência encontra suporte em Krug et al. (2019a, p. 233) que constataram que "[a] dificuldade na gestão da aula [...]" é uma das dificuldades pedagógicas de professores de EF na EB, em diversas fases da carreira. Já Krug (2019b) destaca que o 'pano de fundo', isto é, o que está por trás das dificuldades na gestão da aula do cotidiano educacional, é a precarização do trabalho docente em EF na EB. Assim sendo, podemos inferir que 'não ter conhecimento sobre gestão de aula, ao ser uma dificuldade que aponta para a precarização do trabalho docente pode, com certeza, vir a ser uma implicação de interferência negativa na prática pedagógica dos professores de $\mathrm{EF}$ da EB, em diferentes fases da carreira'. Entretanto, frente a esse cenário inferido, Krug et al. (2019c, p. 27) salientam que "[s]aber mais sobre gestão de aula [...]" é uma das necessidades formativas do professor de EF da EB. Nesse sentido, citamos Arends (2005, p. 555) que diz que a gestão de aula envolve "os modos pelos quais os professores organizam e estruturam suas aulas de aula, com o propósito de maximizar a cooperação e o envolvimento dos alunos e diminuir o comportamento disruptivo". Já Krug (2019b, p. 4) coloca que saber sobre gestão de aula "[...] pode contribuir para orientar a qualidade da atuação docente na escola". Dessa forma, podemos inferir que 'saber mais sobre gestão de aula, ao ser uma necessidade formativa que contribui para a qualidade da atuação docente pode, com certeza, vir a ser uma implicação de interferência positiva na prática pedagógica dos professores de EF da EB, em diferentes fases da carreira, tornando-se assim, um saber da experiência'.

Assim, estes foram os saberes da experiência e suas implicações na prática pedagógica, nas percepções dos professores de EF da EB estudados, em diferentes fases da carreira docente.

Ao efetuarmos uma 'análise geral', sobre as percepções dos professores de EF da EB estudados, nas/em diferentes fases da carreira docente (conforme quadro 1), relativamente aos saberes da experiência e suas implicações na prática pedagógica constatamos que uma 'metade' (quatro do total de oito) dos saberes da experiência está 'ligada aos próprios professores, ou seja, a si mesmos'*** (itens: $4 ; 5 ; 6$ e 8 ) e outra 'metade' (quatro do total de oito) está dividida em 'duas partes', uma (três do total de quatro) 'ligada aos alunos da EB’** 
(itens: $2 ; 3$ e 7) e outra (uma do total de quatro) 'ligada à estrutura da escola/sistema educacional'* (item: 1). Vale ainda ressaltar que os saberes da experiência (conforme quadro 1), de forma 'geral', tiveram sessenta e oito citações, sendo vinte e nove 'ligadas aos alunos da EB`**, vinte 'ligadas aos próprios professores, ou seja, a si mesmos’*** e dezenove 'ligadas à estrutura da escola/sistema educacional'***. A partir dessas constatações, podemos inferir que, de forma geral, 'os saberes da experiência estão ligados à diversos fatores, tanto fatores relacionados internamente à prática pedagógica dos professores (aos alunos e aos próprios professores - itens: $2 ; 3 ; 4 ; 5 ; 6 ; 7$ e 8 ; quarenta e oito citações), quanto à fatores relacionados externamente à prática pedagógica dos professores' (estrutura da escola/sistema educacional - item: 1 ; dezenove citações).

Ao realizarmos uma 'análise parcial', isto é, em diferentes fases da carreira docente (conforme quadro 1), relativamente aos saberes da experiência e suas implicações na prática pedagógica, constatamos:

a) 'sobre a quantidade de ocorrência dos saberes da experiência e suas implicações na prática pedagógica' - a 'existência' de quatro saberes da experiência na 'fase de entrada na carreira' (itens: $1 ; 2 ; 6$ e 8), cinco na 'fase de estabilização' (itens: $1 ; 2 ; 3 ; 6$ e 7), seis na 'fase de diversificação' (itens: $1 ; 2 ; 3 ; 4 ; 5$ e 7), sete na 'fase de serenidade e/ou conservantismo' (itens: $1 ; 2 ; 3 ; 4 ; 5 ; 6$ e 7) e também sete na 'fase de desinvestimento' (itens: $1 ; 2 ; 3 ; 4 ; 5 ; 6$ e 7). Dessa forma, inferimos 'a ocorrência da construção de saberes da experiência em todas as fases da carreira docente e, de certa forma, mantendo uma regularidade média de construção dos mesmos' (de quatro a sete). Ainda é pertinente destacar que a 'quantidade de citações' de saberes da experiência, na 'fase de entrada na carreira' foi de quatro, na 'fase de estabilização' de oito, na 'fase de diversificação' de dezesseis, na 'fase de serenidade e/ou conservantismo' de dezenove e na 'fase de desinvestimento' de vinte e um. Nesse sentido, podemos inferir que 'a fase de desinvestimento foi onde aconteceu o maior número de citações de saberes da experiência e que ocorreu um nítido aumento do número de citações com o passar das fases da carreira docente' (de quatro para vinte e uma);

b) 'sobre os principais saberes da experiência e suas implicações na prática pedagógica - em 'todas' as fases da carreira docente, isto é, na 'entrada na carreira' (uma citação), na 'estabilização' (três citações), na 'diversificação' (cinco citações), na 'serenidade e/ou conservantismo' (cinco citações) e no 'desinvestimento' (cinco citações) o principal saber da experiência foi 'saber lidar com as condições de trabalho difíceis/precárias' (item: 1). Dessa maneira, inferimos que 'saber lidar com as condições de trabalho difíceis/precárias apresenta- 
se como o principal saber da experiência com implicações na prática pedagógica em todas as fases da carreira docente'; e,

c) 'sobre os saberes da experiência e os fatores a que estão ligados' - na 'fase de entrada na carreira' estão 'ligados aos próprios professores, ou seja, a si mesmos'*** em dois saberes da experiência com duas citações e, a partir daí estão 'ligados aos alunos da EB'** (na 'fase de estabilização' em três saberes da experiência com quatro citações; na 'fase de diversificação' em três saberes da experiência com seis citações; na 'fase de serenidade e/ou conservantismo' com três saberes da experiência com oito citações; e, na 'fase de desinvestimento' em três saberes da experiência com dez citações). Nessa direção de constatação, inferimos que 'na fase de entrada na carreira os saberes da experiência estão, principalmente, ligados aos próprios professores, ou seja, a si mesmo e nas outras fases da carreira docente (estabilização; diversificação; serenidade e/ou conservantismo; e, desinvestimento) estão, principalmente, ligados aos alunos da EB'.

\section{AS CONSIDERAÇÕES FINAIS}

Pela análise das informações obtidas temos a destacar que os saberes da experiência e suas implicações na prática pedagógica, nas percepções dos professores de EF da EB estudados, em diferentes fases da carreira, de 'forma geral', foram os seguintes: 1) 'saber lidar com as condições de trabalho difíceis/precárias'; 2) 'saber lidar com os comportamentos indisciplinados dos alunos'; 3) 'saber lidar com a falta de interesse dos alunos pelas atividades propostas'; 4) 'saber evitar os conflitos com os colegas de trabalho'; 5) 'saber trabalhar coletivamente na escola'; 6) 'saber fazer um bom planejamento de ensino para as aulas de EF'; 7) 'saber ter o controle/domínio da turma de alunos'; e, 8) 'saber mais sobre gestão de aula'.

Este rol de saberes da experiência, de 'forma geral', aponta para a constatação de que uma 'metade' destes saberes está 'ligada aos próprios professores, ou seja, a si mesmos' e a outra 'metade' está 'ligada aos alunos da EB' e 'ligada à estrutura da escola/sistema educacional'. Frente a esse contexto, destacamos que, segundo Pimenta (2002), os saberes da experiência são aqueles advindos da história de vida, das relações construídas entre os docentes, das experiências que os mesmos obtiveram ao longo de suas vidas no contato com a escola, e, por isso a complexidade da origem dos mesmos.

Também pela análise das informações obtidas, em uma 'análise parcial', relativa às fases da carreira docente, constatamos que: a) 'ocorreu a construção de saberes da experiência em todas as fases da carreira docente', mantendo-se um aumento da quantidade de ocorrência 
dos mesmos com o passar do tempo de magistério. Nesse sentido, Tardif e Raymond (2000) colocam que a dimensão temporal do trabalho e a experiência da prática da profissão na trajetória docente é crucial na aquisição do sentimento de competência e na implantação das rotinas de trabalho, em outras palavras na estruturação da prática; b) 'saber lidar com as condições de trabalho difíceis/precárias foi o principal saber da experiência em todas as fases da carreira docente'; e, c) 'os saberes da experiência estão, prioritariamente, ligados aos próprios professores, ou seja, a si mesmos, na fase de entrada na carreira (itens: 6 e 8 com duas citações) e ligados aos alunos da EB nas fases restantes' (estabilização - itens: 2; 3 e 7 com quatro citações; diversificação - itens: 2; 3 e 7 com seis citações; serenidade e/ou conservantismo - itens: 2; 3 e 7 com oito citações; e, desinvestimento - itens: 2; 3 e 7 com dez citações).

Ainda constatamos que 'todos os saberes da experiência tem como origem as dificuldades encontradas, pelos professores de EF da EB estudados, na prática pedagógica que possuem implicações negativas na atuação docente, bem como os saberes da experiência promovem facilidades na prática pedagógica com implicações positivas na docência'. Esse fato está em consonância com o dito por Nascimento et al. (2019) de que os saberes produzidos a partir da experiência pode favorecer na superação das dificuldades encontradas no cotidiano docente.

Neste contexto, podemos afirmar que todos os saberes da experiência dos professores de EF da EB estudados estão ligados às suas necessidades formativas, pois, segundo Bernardi e Krug (2008, p. 74),

[...] os saberes da experiência do professor, aos quais ele constrói na sua relação com a sua realidade, vêm atender às necessidades formativas, lacunas deixadas pela sua formação inicial, assim tendo uma grande importância no momento de rever estes conhecimentos iniciais de forma a estar avaliando-as e validando-os na sua atuação docente, objetivando estabelecer uma Educação Física Escolar voltada [...] (aos alunos) (acréscimo nosso).

Frente a este quadro constatado no presente estudo, concordamos com Tardif (20022) que afirma que os saberes experenciais são resultados de uma construção individual, compartilhados e legitimados através da socialização profissional.

Para finalizar, lembramos que é preciso considerar que este estudo fundamentou-se nas especificidades e nos contextos de uma cidade em particular e de professores de EF da EB em específico e que seus achados não podem ser generalizados e sim encarados como uma possibilidade de ocorrência. 


\section{REFERÊNCIAS}

ALMEIDA, Claudio Bispo de; OPPA, Deraldo Ferreira; MORETTI-PIRES, Rodrigo Otávio. Estudo de caso. In: SANTOS, Saray Giovana dos; MORETTI-PIRES, Rodrigo Otávio (Orgs.). Métodos e técnicas de pesquisa qualitativa aplicada à Educação Física. Florianópolis: Tribo da Ilha, 2012. p. 143-148.

ARAGÃO, Paula; MORETTI-PIRES, Rodrigo Otávio. Questionários. In: SANTOS, Saray Giovana dos; MORETTI-PIRES, Rodrigo Otávio (Orgs.). Métodos e técnicas de pesquisa qualitativa aplicada à Educação Física. Florianópolis: Tribo da Ilha, 2012. p. 184-187.

ANTUNES, Fabiana Ritter; KRUG, Hugo Norberto. Resenhando o livro Saberes Docentes e Formação Profissional de Maurice Tardif. Revista P@rtes, São Paulo, p. 1-5, ago. 2011. Disponível em: http://www.partes.com.br/educacao/resenhas/saberesdocentes.asp. Acesso em: 21 nov. 2019.

ARENDS, Richard. Aprender a ensinar. Lisboa: McGraw-Hill, 2005.

BERNARDI, Ana Paula; KRUG, Hugo Norberto. Saberes docentes e a organização didáticopedagógica da Educação Física na Educação Infantil. In: KRUG, Hugo Norberto. (Org.). Os professores de Educação Física e sua formação. Santa Maria: Universidade Federal de Santa Maria, Centro de Educação, Programa de Pós-Graduação em Educação, Grupo de Estudos e Pesquisas em Educação Física, 2008. p. 63-76. (Coleção Formação de Professores de Educação Física; v. 3).

BERRIA, Juliane; CONFORTIN, Susana Cararo; SANT'ANA, Jader; MORETTI-PIRES, Rodrigo Otávio; SANTOS, Saray Giovana dos. Seleção dos informantes. In: SANTOS, Saray Giovana dos; MORETTI-PIRES, Rodrigo Otávio (Orgs.). Métodos e técnicas de pesquisa qualitativa aplicada à Educação Física. Florianópolis: Tribo da Ilha, 2012. p. 157-168.

CASAROTTO, Verônica Jocasta; KRUG, Hugo Norberto. O processo de construção dos saberes docentes de professores de Educação Física atuantes em escolas de Educação Especial. Revista Holos, Natal, a. 32, v. 08, p. 328-378, 2016.

CONCEIÇÃO, Victor Julierme Santos da; SOUSA, T.; KRUG, Hugo Norberto. Saberes docentes e atuação profissional do professor de Educação Física no ensino regular com alunos com necessidades educacionais especiais incluídos. Revista Digital Lecturas: Educación Física y Deportes, Buenos Aires, a. 15, n. 148, p. 1-6, sep. 2010. Disponível em: http://www.efdeportes.com/efd148/atuacao-profissional-com-alunos-com-necessidades... . Acesso em: 21 nov. 2019.

CONCEIÇÃO, Victor Julierme Santos da; KRUG, Hugo Norberto; VENSON, Edna. Mobilizando saberes docentes na Educação Física Escolar: a construção do conhecimento sobre inclusão. Revista Educação Especial, Santa Maria, v. 26, n. 46, p. 465-484, mai./ago. 2013. 
CONTREIRA, Clairton Balbueno; KRUG, Hugo Norberto. Os impactos nos saberes docentes dos professores do CEFD/UFSM após a divisão curricular em Licenciatura e Bacharelado. Revista Saberes, Natal, v. 1, n. 12, p. 225-250, set. 2015.

FRANCO, Maria Laura Puglisi Barbosa. Análise de conteúdo. Brasília: Líber Livro, 2008.

HUBERMAN, Michaël. O ciclo de vida profissional dos professores. In: NÓVOA, António (Org.). Vidas de professores. Porto: Porto Editora, 1995.

ILHA, Franciele Roos da Silva; MARQUES, Marta Nascimento; KRUG, Hugo Norberto. O planejamento e o desempenho dos acadêmicos de Educação Física na sua Prática de Ensino: um estudo de caso no Centro de Educação Física e Desportos da Universidade Federal de Santa Maria. In: CONGRESSO DE EDUCAÇÃO, ARTE E CULTURA, 2., 2009, Santa Maria. Anais, Santa Maria: UFSM, 2009.

KRÜGER, Leonardo Germano; KRUG, Hugo Norberto. As concepções da formação profissional da Licenciatura em Educação Física: trajetórias docentes e suas perspectivas contributivas. In: KRUG, Hugo Norberto (Org.). Os professores de Educação Física e sua formação. Santa Maria: Universidade Federal de Santa Maria, Centro de Educação, Programa de Pós-Graduação em Educação, Grupo de Estudos e Pesquisas em Educação Física, 2008. p. 30-38. (Coleção Formação de Professores de Educação Física; v. 3).

KRUG, Hugo Norberto. A reflexão na prática pedagógica do professor de Educação Física, 1996. Dissertação (Mestrado em Ciência do Movimento Humano) - Universidade Federal de Santa Maria, Santa Maria, 1996.

KRUG, Hugo Norberto. Teorizando o processo de construção do conhecimento prático do professor... de Educação Física Escolar. Revista Digital Lecturas: Educación Física y Deportes, Buenos Aires, a. 20, n. 204, p. 1-11, may. 2015. Disponível em: http://www.efdeportes.com/efd204/conhecimento-pratico-do-professor-de-educacaofisica.htm. Acesso em: 21 nov. 2019.

KRUG, Hugo Norberto. Os fatores que dificultam e que facilitam a prática pedagógica de professores de Educação Física da Educação Básica. Revista Gestão Universitária, Belo Horizonte, p. 1-13, jul. 2019a. Disponível em:

http://www.gestaouniversitaria.com.br/artigos/os-fatores-que-dificultam-e-que-facilitam-apratica-pedagogica-de-professores-de-educacao-fisica-da-e... . Acesso em: 13 out. 2020.

KRUG, Hugo Norberto. As dificuldades na gestão de aula em diversas fases da carreira de professores de Educação Física da Educação Básica. Revista Gestão Universitária, Belo Horizonte, p. 1-13, out. 2019b. Disponível em:

http://www.gestaouniversitaria.com.br/artigos/as-dificuldades-na-gestao-de-aula-em-diversasfases-da-carreira-de-professores-de-educacao-fisica-da... . Acesso em: 19 out. 2020. 
KRUG, Hugo Norberto. Apontamentos comparativos das características do bom professor de Educação Física da Educação Básica e da Educação Superior nas percepções de acadêmicos de Licenciatura em Educação Física. Revista Gestão Universitária, Belo Horizonte, p. 1-13, abr. 2020. Disponível em: http://www.gestaouniversitaria.com.br/artigos/apontamentoscomparativos-das-caracteristicas-do-bom-professor-de-educacao-fisica-da-educacao-ba.... . Acesso em: 20 out. 2020.

KRUG, Hugo Norberto; TELLES, Cassiano; KRUG, Rodrigo de Rosso; CONCEIÇÃO, Victor Julierme Santos da. Estágio Curricular Supervisionado em Educação Física: os saberes experenciais dos estagiários. Revista Querubim, Niterói, a. 11, n. 25, v. 2, p. 79-84, 2015.

KRUG, Hugo Norberto; KRUG, Marilia de Rosso; KRUG, Rodrigo de Rosso; TELLES, Cassiano. Os saberes da formação profissional inicial necessários à prática docente nos Estágios Curriculares Supervisionados na Educação Básica na percepção de acadêmicos de Licenciatura em Educação Física. Revista Gestão Universitária, Belo Horizonte, p. 1-11, mar. 2016a. Disponível em: http://www.gestaouniversitaria.com.br/artigos/os-saberes-daformacao-profissional-inicial-necessarios-a-pratica-docente-nos-estagios-curriculares-sup... . Acesso em: 27 out. 2019.

KRUG, Hugo Norberto; KRUG, Rodrigo de Rosso; TELLES, Cassiano; CONCEIÇÃO, Victor Julierme Santos da. A cultura da Educação Física Escolar. Revista Temas em Educação, João Pessoa, v. 25, n. 1, p. 61-77, jan./jun. 2016 b.

KRUG, Hugo Norberto; CONCEIÇÃO, Victor Julierme Santos da; KRUG, Marilia de Rosso; TELLES, Cassiano; KRUG, Rodrigo de Rosso; FLORES, Patric Paludett. A prática pedagógica de professores de Educação Física na Educação Básica: os seus dilemas e sua gestão. Revista Querubim, Niterói, a. 12, n. 29, v. 02, p. 19-24, 2016 c.

KRUG, Hugo Norberto; KRUG, Marilia de Rosso; KRUG, Rodrigo de Rosso; TELLES, Cassiano; FLORES, Patric Paludett. Os saberes do bom professor formador em Educação Física na percepção de acadêmicos concluintes da graduação. Revista Querubim, Niterói, a. 13, n. 33, v. 02, p. 90-96, 2017.

KRUG, Hugo Norberto; KRUG, Marilia de Rosso; KRUG, Rodrigo de Rosso; KRUG, Moane Marchesan. Os desafios docentes no cotidiano educacional em diferentes fases da carreira de professores de Educação Física da Educação Básica. Revista Querubim, Niterói, a. 15, n. 37 , v. 4, p. 33-41, 2018.

KRUG, Hugo Norberto; KRUG, Rodrigo de Rosso; KRUG, Marilia de Rosso; KRUG, Moane Marchesan; TELLES, Cassiano. As dificuldades pedagógicas em diversas fases da carreira de professores de Educação Física da Educação Básica. Horizontes - Revista de Educação, Dourados, v. 7, n. 13, p. 223-246, jan./jun. 2019a.

KRUG, Hugo Norberto; KRUG, Marilia de Rosso; KRUG, Rodrigo de Rosso; KRUG, Moane Marchesan; TELLES, Cassiano. A docência em Educação Física na Educação Básica: os 
fatores indicativos de (in)satisfação profissional em diferentes fases da carreira. Revista Querubim, Niterói, a. 15, n. 38, v. 4, p. 13-22, 2019 b.

KRUG, Hugo Norberto; KRUG, Marilia de Rosso; KRUG, Rodrigo de Rosso; KRUG, Moane Marchesan; TELLES, Cassiano. Necessidades formativas de professores de Educação Física iniciantes na Educação Básica. Revista Querubim, Niterói, a. 15, n. 38, v. 4, p. 23-31, 2019c.

KRUG, Hugo Norberto; KRUG, Marilia de Rosso; KRUG, Rodrigo de Rosso; KRUG, Moane Marchesan; TELLES, Cassiano. O clima escolar e suas implicações para o trabalho docente em Educação Física na Educação Básica. Revista Almanaque Multidisciplinar de Pesquisa, Rio de Janeiro, a. VI., v. 1, n. 2, p. 130-156, 2020.

KRUG, Rodrigo de Rosso; KRUG, Hugo Norberto. Os saberes necessários à prática docente em Educação Física Escolar na percepção dos acadêmicos da Licenciatura em Educação Física do CEFD/UFSM. Revista Digital Lecturas: Educación Física y Deportes, Buenos Aires, a. 15, n. 150, p. 1-8, nov. 2010. Disponível em: http://www.efdeportes.com/efd150/ossaberes-necessarios-em-educacao-fisica... . Acesso em: 21 nov. 2019.

LARROSA, Jorge. Notas sobre a experiência e o saber da experiência. Revista Brasileira de Educação, n. 19, jan./abr. 2002.

LOURENCETTI, Gisela do Carmo; MIZUKAMI, Maria da Graça Nicoletti. Dilemas de professores em práticas cotidianas. In: MIZUKAMI, Maria da Graça Nicoletti; REALI, Aline Maria de Medeiros Rodrigues (Orgs.). Aprendizagem profissional da docência: saberes, contextos e práticas. São Carlos: EdUFSCar, 2002. p. 49-59.

MORETTI-PIRES, Rodrigo Otávio; SANTOS, Saray Giovana dos. Sobre pesquisa qualitativa. In: SANTOS, Saray Giovana dos; MORETTI-PIRES, Rodrigo Otávio (Orgs.). Métodos e técnicas de pesquisa qualitativa aplicada à Educação Física. Florianópolis: Tribo da Ilha, 2012. p. 15-27.

NASCIMENTO, Ana Quiovetti do; FAUSTO, Ilma Rodrigues de Souza; SANTOS, Marina Santana dos; FERREIRA, Maria Rosenilda Pires; SANTOS, Sirlei Soares dos; BOSQUÊ JÚNIOR, Carlos Alberto. Os saberes da experiência e suas implicações na formação docente. Revista Gestão Universitária, Belo Horizonte, p. 1-10, nov. 2019. Disponível em: http://www.gestaouniversitaria.com.br/artigos/os-saberes-da-experiencia-e-suas-implicacoesna-formacao-docent... . Acesso em: 21 nov. 2019.

PIMENTA, Selma Garrido. O estágio na formação de professores. 5. ed. São Paulo: Cortez, 2002.

REBOLO, Flavinês. Fontes e dinâmicas do bem-estar docente: os quatro componentes de um trabalho felicitário. In: REBOLO, Flavinês; TEIXEIRA, Lenny Rodrigues Martins;

PERRELLI, Maria Aparecida de Souza (Orgs.). Docência em questão: discutindo trabalho e formação. Campinas: Mercado de Letras, 2012. 
TARDIF, Maurice. Saberes docentes e formação profissional. 3. ed. Petrópolis: Vozes, 2002.

TARDIF, Maurice; RAYMOND, Danielle. Saberes, tempo e aprendizagem do trabalho no magistério. Revista Educação \& Sociedade, Campinas, v. 21, n. 73, p. 209-244, dez. 2000.

TELLES, Cassiano; KRUG, Rodrigo de Rosso; CONCEIÇÃO, Victor Julierme Santos da; KRUG, Hugo Norberto. Os saberes necessários ao bom professor de Educação Física Escolar na percepção dos acadêmicos ingressantes da graduação. Revista Gestão Universitária, Belo Horizonte, p. 1-14, mar. 2015. Disponível em: http://www.gestaouniversitaria.com.br/artigoscientificos/os-saberes-necessarios-ao-bom-professor-de-educacao-fisica-escolar-napercepcao-dos-aca... . Acesso em: 27 out. 2019. 